\title{
Scaled charges at work: Salting out and interfacial tension of methane with electrolyte solutions from computer simulations
}

\author{
S. Blazquez a , I.M. Zeron ", M.M. Conde ${ }^{\text {b }}$, J.L.F. Abascal a , C. Vega ${ }^{\text {a, * }}$ \\ a Departamento de Química Física I, Facultad de Ciencias Químicas, Universidad Complutense de Madrid, 28040, Madrid, Spain \\ b Departamento de Ingeniería Química Industrial y Medio Ambiente, Escuela Técnica Superior de Ingenieros Industriales, Universidad Politécnica de Madrid, \\ 28006, Madrid, Spain
}

\section{A R T I C L E I N F O}

\section{Article history:}

Received 5 December 2019

Received in revised form 24 February 2020

Accepted 1 March 2020

Available online 5 March 2020

\section{Keywords:}

Salting out

Methane-water interface

Computer simulation

Force field

Electrolytes

\begin{abstract}
A B S T R A C T
The solubility of methane in water decreases when a small amount of salt is present. This is usually denoted as the salting out effect (i.e., the methane is expelled from the solution when it contains small amounts of salt). The effect is important, for instance the solubility is reduced by a factor of three in a $4 \mathrm{~m}(\mathrm{~mol} / \mathrm{kg}) \mathrm{NaCl}$ solution. Some years ago we showed that the salting out effect of methane in water can be described qualitatively by molecular models using computer simulations. However the salting out effect was overestimated. In fact, it was found that the solubility of methane was reduced by a factor of eight. This points to limitations in the force field used. In this work we have carried out direct coexistence simulations to describe the salting out effect of methane in water using a recently proposed force field (denoted as Madrid-2019) based on the use of scaled charges for the ions and the TIP4P/2005 force field for water. For $\mathrm{NaCl}$ the results of the Madrid-2019 force field significantly improve the description of salting out of methane. For other salts the results are quite reasonable. Thus the reduction of the charge of the ions also seems to be able to improve the description of salting out effect of methane in water. Besides this we shall show that the brine-methane interface exhibits an increased interfacial tension as compared to that of the water-methane system. It is well known that electrolytes tend to increase the surface tension of liquid water, and this seems also to be the case for the interface between water and methane.
\end{abstract}

() 2020 Elsevier B.V. All rights reserved.

\section{Introduction}

The solubility of a gas in water can be enhanced (salting in) or reduced (salting out) by the presence of a certain solute. Electrolyte solutions (and in particular those formed by $\mathrm{NaCl}$ and water) are of significant practical interest [1-8]. In general, the solubility of gases in water decreases with the addition of salt (i.e. salting out). The effect is important and well known from an experimental point of view. Methane is a gas of considerable interest. For instance, methane hydrates are formed in the proximity of the coast $[9,10]$. Thus, methane hydrates are often found in solutions containing $\mathrm{NaCl}$ and, therefore, the impact of salt on the solubility of methane is also of significant practical interest.

The problem of salting out has been addressed from a theoretical perspective by Graziano [11]. Computer simulations could be

\footnotetext{
* Corresponding author.

E-mail address: cvega@quim.ucm.es (C. Vega).
}

useful in understanding and predicting this effect. To study the salting out of methane in water, a good force field for methane in water (in the absence of salt) is first required. It can be stated that at this point we have reasonable force fields for both molecules. Methane can be described reasonably well by a Lennard-Jones (LJ) site [12,13], and water by the TIP4P/2005 model [14]. Of course having a good force field for pure methane and water fluids does not guarantee that the solubility of methane in water is accurately predicted. If one wants to reproduce the experimental values of the solubility, one also needs to tailor the cross methane-water interactions. In fact we have shown in the past $[15,16]$ that to predict accurate values of the chemical potential and the solubility of methane the strength of the methane-water interaction must be increased by approximately seven per cent [15]. The enhancement seems an effective way of introducing the polarization undergone by the molecule of methane when solvated by water. Interestingly a similar increase in the strength of the interaction between protein atoms and water (as described by the TIP4P/2005 model) has dramatically improved the description of intrinsically disordered 
proteins in water as shown by Best et al. [17].

Once the interactions in the binary methane/water system are satisfactorily described, a good force field for the ions in water is needed to study salting out effects. A quick search in the literature results in a number of force fields names [18-45], like AMBER, GROMOS, CHARMM and OPLS-AA, used by a large scientific community (see Refs. [46-48] for details on the parameters of these force fields). However, in the recent years a serious problem with these force fields has emerged. For most of them $\mathrm{NaCl}$ spontaneously precipitates even at concentrations as low as $1.5 m$ or $2 m$ [46] (the solubility limit of $\mathrm{NaCl}$ in water is about $6.1 \mathrm{~m}$ ). Since spontaneous precipitation of salt in water occurs for high supersaturations (i.e., when the concentration is about five times higher than the solubility) [49,50], this indicates that the solubility of these force fields is well below $0.5 \mathrm{~m}$. For instance, for the OPLS model of $\mathrm{NaCl}$ in combination with the SPC/E [51] water model, the solubility was found to be as small as $0.02 \mathrm{~m}$ [52]. Thus, the results obtained with these force fields will not be too useful as the ions will cluster in water in an artificial way. Reports on ion-clustering have already been documented in many papers over the last 20 years. In fact, in simulations the precipitation of $\mathrm{NaCl}$ [30,53-56], $\mathrm{KCl}$ [32,57], $\mathrm{CaCl}_{2}$ [58], $\mathrm{Na}_{2} \mathrm{SO}_{4}$ [59] and $\mathrm{Li}_{2} \mathrm{SO}_{4}$ [60] at concentrations below the solubility limit has been found. It is clear that a good force field for ions in water should provide reasonable values for the solubility. Over the last few yerre thanks to the works of Smith, Nezbeda and coworkers (61-6 3 ), Panagiotopoulos and coworkers [61-64] and also ourselves $[65,66]$ it has become clear that, when modelling salts in water, solubility matters. Some other widely used force fields also have low values of the solubility of $\mathrm{NaCl}$ in water as it is the case for the Smith-Dang [24] model with a solubility around $0.6 \mathrm{~m}$ and that of Joung-Cheatham [32] with a solubility around $3.7 m[43,63,66]$ (using the SPC/E model for water). Jiang et al. [67] revealed that the polarizable BK3 models $[42,68]$ can give reasonable estimates for most of the properties of interest although it would mean an increase of 5-10 times the computational cost with respect to non-polarizable models. In the meantime, Orozco et al. [69] performed an extensive study involving several force field combinations in order to determine the best alternatives for molecular simulation in $\mathrm{H}_{2} \mathrm{O}-\mathrm{NaCl}$ systems with charges \pm 1 for the ions.

In recent years a debate is taking place about the values of the charges to be used when describing the ions in water solutions. Should one accept the integer value, i.e. \pm 1 (in electron units) or should one use a scaled value of the charge, i.e 0.75 or 0.85 ? The origin of this discussion is as follows. In 2012 Yethiraj and coworkers [70] showed that none of the many models tested (both polarizable and non-polarizable) could reproduce the experimentally observed trends for the concentration dependence of the diffusion coefficient of water in several electrolyte solutions, indicating that probably the ion-water interaction was too strong. Then Kann and Skinner [71] followed a suggestion of Leontyev and Stuchebrukhov [72-77] and described electrolytes in water using scaled charges. The idea of using scaled charges for ions in water is usually denoted as the electronic continuum correction (ECC). It can also be regarded as a consequence of the fact that the potential energy and the dipole moment surfaces may need different parameters to be described by empirical force fields [78,79]. Soon other groups, as that of Jungwirth [58,80,81], Barbosa [82], and Wang $[83,84]$ adopted this idea. We recently proposed a force field for $\mathrm{NaCl}$ in water that uses scaled charges for the ionic components, and extended the concept to other electrolytes in 2019 proposing the so called Madrid-2019 [85,86] force field for electrolytes in water. Densities and transport properties seem to be better described by the use of scaled charges [86,87]. The justification behind this approach is to assume that there is a certain transfer of charge from the water molecules in the hydration layer to the ions.

In this work we intend to address the problem of salting out of methane in water following up on our previous work [16] on this problem with two goals in mind. The first one is to test if the Madrid-2019 force field can describe the corresponding experimental results. The second one is to throw light on a more fundamental question in the modelling of ions in water: are scaled charges superior when describing the salting out effects than models that use unit charges? Thus our study aims to describe a system of high interest and also to bring to the community a problem that can be very useful in improving our understanding of our success/limitations in the modelling of ions in water.

\section{Model}

In this work we shall evaluate the solubility of methane in aqueous electrolyte solutions of different salts. In particular we shall consider the following salts: $\mathrm{NaCl}, \mathrm{KCl}, \mathrm{MgCl}_{2}, \mathrm{CaCl}_{2}, \mathrm{Na}_{2} \mathrm{SO}_{4}$, $\mathrm{K}_{2} \mathrm{SO}_{4}$ and $\mathrm{MgSO}_{4}$. We shall use a rigid non-polarizable force field. The pairwise interaction potential between atoms is given by an electrostatic (coulombic) contribution and a van der Waals interaction represented by the LJ potential:

$u\left(r_{i j}\right)=\frac{1}{4 \pi \varepsilon_{0}} \frac{q_{i} q_{j}}{r_{i j}}+4 \varepsilon_{i j}\left[\left(\frac{\sigma_{i j}}{r_{i j}}\right)^{12}-\left(\frac{\sigma_{i j}}{r_{i j}}\right)^{6}\right]$

where, $q_{i}$ is the ionic charge, $\varepsilon_{0}$ is the vacuum permittivity, $\varepsilon_{i j}$ the well depth energy of the LJ potential, and $\sigma_{i j}$ the LJ diameter.

To describe water we shall use the TIP4P/2005 model developed by Abascal and Vega (14) which is a reliable model of water [88-91]. This model is based on the TIP4P water proposed by Jorgensen et al. [92] as TIP4P like models give good predictions for the melting point and the phase diagram of water [93-96]. TIP4P/2005 water has four atoms, two hydrogen with charge $\mathrm{q}_{H}$, one oxygen which is a $\mathrm{LJ}$ site and a site $\mathrm{M}$, near the oxygen atom on the symmetric axis, without mass but with charge $q_{M}$. The TIP4P/2005 water geometry is given by the following parameters: oxygenhydrogen distance, $d_{O H}=0.9572 \AA$, oxygen-M distance, $d_{O M}=0.1546 \AA$ and angle $\mathrm{H}-\mathrm{O}-\mathrm{H}=104.52^{\circ}$. Methane will be described by a single $\mathrm{LJ}$ site (without partial charge) with the parameters proposed by Guillot and Guissani [12] and Paschek [13]. The Lennard Jones parameters of the interaction between water and methane are obtained from the following expression:

$\sigma_{i j}=\frac{\sigma_{i}+\sigma_{j}}{2}$

$\varepsilon_{i j}=\chi \sqrt{\varepsilon_{i} \cdot \varepsilon_{j}}$

When $\chi=1$ one recovers the so called Lorentz-Berthelot (LB) rules. In previous work we have shown that to describe correctly the solubility of methane in water it is necessary to introduce deviations from the energetic LB combining rule (introducing polarizability in the molecule of methane is another possibility as shown in Ref. [97]). For this reason we shall use the value $\chi=1.07$ for the interaction between methane in water as described in our previous work [15]. The parameters obtained in this way are similar to the ones proposed by Ashbaugh et al. [98] for the methane-TIP4P/2005 water interaction, optimized to describe the experimental properties of methane in water. In fact using this value of $\chi=1.07$, we obtained in this work $0.142 \mathrm{~m}$ for the molality (moles of methane per kilogram of water) of methane in water (at 200 bar and $324.65 \mathrm{~K}$ ) which corresponds to a molar fraction of 0.0025 which is in excellent agreement with the experimental value 0.0024 under 
these conditions $[99,100]$. Several comments are in order regarding the use of $\chi=1.07$ for the methane-water crossed interaction. Firstly, it should be pointed out that this value is appropriate to reproduce the solubility of methane in water when using the TIP4P/ 2005 model of water and a united atom model of methane. Also, when using the SPC/E model of water and the united atom model for methane the value $\chi=1.07$ is adequate to reproduce the solubility of methane in water as will be shown in this work. However, for other water models the optimal value of $\chi$ required to reproduce the solubility of methane in water could be different. Secondly, the value $\chi=1.07$ does not guarantee an accurate description of the mixture methane-water over the entire range of concentrations and properties (vapor-liquid, liquid-liquid equilibria, etc). Further studies are required to test this point. Finally it should be pointed out that the value of $\chi=1.07$ is not able to describe the properties of water in methane at infinite dilution. It has been shown in previous work by Chapman and coworkers $[101,102]$ that to describe the properties of water in methane, a value close to $\chi=1.4$ is more appropriate. In fact the models of this work along with $\chi=1.07$ underestimate the experimental value of the solubility of water in methane by a factor of about $5-8$, which is in line with the previous work of Chapman and coworkers on this issue [101]. Obviously only polarizable models can describe simultaneously the behavior of methane in water at infinite dilution, and the behavior of water in methane at infinite dilution. The summary is that the value of $\chi=1.07$ is an optimal choice to study the salting out of methane in water (i.e methane in water at high dilution) but it may not be the optimal choice for other compositions (certainly not for the behavior of water in methane at high dilution).

To describe salts in water we shall use the recently developed Madrid-2019 force field [86]. This force field was developed to represent ions in water as described by the TIP4P/2005 model. This new model uses the idea of scaling charges to account for the polarization of electrolytes in water. The charge assigned to the ions is reduced to $\pm 0.85 e$ in case of monovalents atoms. This model describes quite well the densities of a number of salts in solution. One may expect that a first necessary (but not sufficient) ingredient to describe the salting out effect is a correct description of the density of both pure water and that of the salt solution. This requirement is satisfied by the Madrid-2019 force field. Let us mention that in 2017 we published a model for $\mathrm{NaCl}$ that was denoted as the Madrid model [85]. The Madrid model also uses the scaling of the charges with the value of $\pm 0.85 e$. Whereas in the Madrid model only properties of $\mathrm{NaCl}$ were considered in the target set, in the case of the Madrid-2019 the properties of a number of salts (containing either $\mathrm{Na}$ and/or $\mathrm{Cl}$ ) were included in the target set. In any case for $\mathrm{NaCl}$ the differences between the parameters of these two models (Madrid and Madrid-2019) are rather small.

The last ingredient of the force field is a description of the interaction between methane and the ions of the system. We shall simply use the LB combining rules with $\chi=1$ for this interaction. Notice that since the amount of methane in water is small (its solubility is small) and because the number of ions in solution is also not too big, the cross interaction between the gas and the ions probably does not play a key role when describing the salting out effect (at least for concentrations below $2 \mathrm{~m}$ ).

The parameters used in this work for water and methane are collected in Table 1. The force field for the salts studied here are explained in detail in the original work [86].

Some simulations will also be performed with models that use integer charges for the ions (in electron units). In particular we shall perform simulations for the Smith-Dang [24] (SD) model of $\mathrm{NaCl}$ in combination with both TIP4P/2005 and SPC/E models of water(51). We shall also perform simulations for the Joung-Cheatham [32] (JC) model of $\mathrm{NaCl}$ (set of parameters for SPC/E water) in combination
Table 1

Force field parameters of the water and methane models $\mathrm{l}$ sed $\mathrm{i}$ this work. Water molecules are described using the TIP4P/2005 model (R€...1, and SPC/E model (Ref. [51]). LJ interaction parameters for methane are taken from Refs. [12,13].

\begin{tabular}{llll}
\hline Molecule & $q(e)$ & $\sigma(\AA)$ & $\varepsilon(\mathrm{kJ} / \mathrm{mol})$ \\
\hline TIP4P/2005 & & & \\
O & 0 & 3.1589 & 0.7749 \\
$\mathrm{H}$ & 0.5564 & - & - \\
$\mathrm{M}$ & -1.1128 & - & - \\
$\mathrm{SPC} / \mathrm{E}$ & & & 0.6502 \\
$\mathrm{O}$ & -0.8476 & 3.1656 & - \\
$\mathrm{H}$ & 0.4238 & - & 1.2263 \\
Methane & 0 & 3.7300 & \\
$\mathrm{CH}_{4}$ & 0 & &
\end{tabular}

with both the TIP4P/2005 and the SPC/E models of water [51]. Basically we take the parameters for $\mathrm{Na}$ and $\mathrm{Cl}$ ions from the work of Smith and Dang or Joung and Cheatham and used LB combining rules to describe the interaction with TIP4P/2005 water or SPC/E water. These models will be denoted as SD-TIP4P/2005, SD-SPC/E, JC-TIP4P/2005 and JC-SPC/E. Two of these force fields were used in previous works (Refs. [16,103], and [104] for the SD-TIP4P/2005 and Ref. [85] for the JC-TIP4P/2005). We have shown recently that replacing SPC/E by TIP4P/2005 does not change much the solubility (for the JC force field it changes [85] from $3.7 \mathrm{~m}$ to $3.4 \mathrm{~m}$ ). Recently, Döpke et al. [105] revealed that the ion parameters proposed by Joung and Cheatham [32] for the JC-TIP4P/Ew model [106] of water give almost identical results when the TIP4P/Ew model of water is replaced by TIP4P/2005. However, Mester and Panagiotopoulos [107] have shown that the force field of $\mathrm{NaCl}$ designed for TIP4P/Ew has a low solubility (i.e $1.43 \mathrm{~mol} / \mathrm{kg}$ as compared to the experimental value of $6.15 \mathrm{~m}$ ) and for this reason we will not use this model in this work.

For all the models and simulations used in this work we shall use $\chi=1.07$ for the interaction between methane and water (which guarantees good agreement with experiment in the solubility of methane in water both for TIP4P/2005 and SPC/E) and $\chi=1$ for the interaction between ions and methane.

\section{Simulation details}

To study the salting out effect we employed the direct coexistence method [108-111]. A slab of pure water (or salty solution) will be put in contact with a slab of the pure gas along the $z$ axis. Thus the interface will be perpendicular to the $z$ axis. We have carried out molecular dynamics (MD) simulations in GROMACS package [112,113] in the $N p_{z} T$ ensemble. The liquid phase will contain 6660 molecules of water (and a certain number of molecules of salt depending on the molality). The number of molecules in the gas phase will be 1000 . As the solubility of methane in water is small, only a small fraction of these 1000 molecules will dissolve in water (we checked that never more than 100). Our choice for the number of molecules of water, 6660 , is rather convenient since for this number, 120 molecules of salt will correspond to a molality of about $1 \mathrm{~m}$. We used the leap-frog integrator algorithm [114], and a time step of 2 fs to solve the equation of motions. Periodic boundary conditions in all directions were used. The Nosé-Hoover thermostat $[115,116]$ was set with a coupling constant of 2 ps to keep constant the temperature of the system. Anisotropic pressure was applied in the $z$ direction using the Parrinello-Rahman barostat [117] with time constant of 2 ps. For electrostatics and van der Waals interactions the cutoff radii were fixed at $0.9 \mathrm{~nm}$ and long-range corrections in the energy and pressure were applied. The smooth PME method [118] to account for the long-range electrostatic forces was used. To maintain the water geometry the LINCS algorithm 
$[119,120]$ has been applied and SHAKE $[121]$ in the case of sulfate anions. Typically the length of the runs was of about 80 ns. Four independent runs were performed for each considered state presented in this work. The simulations of this work expand up to $6 \mu \mathrm{s}$ of real time for systems having around 8000 molecules. A snapshot of the set-up of our simulations is shown in Fig. 1.

The salting out effect is quantified with the empirical Setchenow equation, which linearizes the logarithm of the ratio of the molality of the gas (methane in our case) in pure water $m_{\text {gas }}^{0}$ and in salt solution $m_{\text {gas }}$, versus the salt molality $m_{\text {salt }}$. This equation is expressed as:

$\ln \left(\frac{m_{\text {gas }}^{0}}{m_{\text {gas }}}\right)=k_{\text {salt }} m_{\text {salt }}$

where $\mathrm{k}_{\text {salt }}$ is the salting out coefficient of the Setchenow equation. The addition of salt induces an exponential decrease in the molality of the gas in the aqueous solution (assuming that $k_{\text {salt }}$ is positive). It is worth mentioning a few words on the thermodynamics of the salting out effect. The solubility of methane in pure water occurs when the chemical potential of the gas $\mu_{\mathrm{CH}_{4}}(T, p$, gas phase) is identical to that in solution:

$$
\begin{aligned}
& \mu_{\mathrm{CH}_{4}}(T, p, \text { gas phase })=\mu_{\mathrm{CH}_{4}}(T, p, \text { solution })=\mu_{C H 4}^{\dagger} \\
& \quad+k \operatorname{Tln}\left(\gamma_{\mathrm{CH}_{4}}^{0} m_{\mathrm{CH}_{4}}^{0}\right)
\end{aligned}
$$

where the superscript zero just reflects that no salt is present in water, $\gamma_{\mathrm{CH}_{4}}^{0}$ and $m_{\mathrm{CH}_{4}}^{0}$ are the activity coefficient and the molality of methane in water respectively and $\mu_{\mathrm{CH} 4}^{\dagger}$ represents the Henry's law standard chemical potential of methane. When salt is added then one obtains:

$\mu_{\mathrm{CH}_{4}}(T, p$, gas phase $)=\mu(T, p$, solution $)=\mu_{C H 4}^{\dagger}+k \operatorname{Tln}\left(\gamma_{\mathrm{CH}_{4}} m_{\mathrm{CH}_{4}}\right)$

by subtracting these two equations (after noticing that the chemical potential of methane in the gas phase is almost identical in both cases, since the presence of the salt does not affect much the chemical potential of the methane in the gas phase) one obtains:

$\ln \left(m_{\mathrm{CH}_{4}}^{0} / m_{\mathrm{CH}_{4}}\right)=\ln \left(\gamma_{\mathrm{CH}_{4}} / \gamma_{\mathrm{CH}_{4}}^{0}\right)$

Using the Setchenow relation one obtains: $\ln \left(\gamma_{\mathrm{CH}_{4}}^{0}\right)+k_{\text {salt }} m_{\text {salt }}=\ln \left(\gamma_{\mathrm{CH}_{4}}\right)$

According to this equation the activity coefficient of methane in water increases exponentially with the addition of salt. Thus capturing the salting out effect requires a correct description of the activity coefficient of methane in salty water. We have shown recently that scaled charges are able to describe much better the activity coefficient of $\mathrm{NaCl}$ in water and the char $: n$ the chemical potential of water due to the addition of salt.( $\{8)$ he salting out coefficient will inform us if the model is also able to evaluate the activity coefficient of methane in the salty solution.

\section{Results}

We shall now present the results of salting out of methane obtained in this work for two types of models. The first family is formed by models in which the charge assigned to the ions is \pm 1 (in electron units) as is the case for the SD-TIP4P/2005, SD-SPC/E, JCTIP4P/2005 and JC-SPC/E force fields. The second type of force fields are based on the use of scaled charges for the $\mathrm{Na}^{+}$and $\mathrm{Cl}^{-}$ ions as is the case for the Madrid and Madrid-2019 force fields. In Fig. 2 the results for the salting out of methane in an aqueous $\mathrm{NaCl}$ solution at 200 bar are shown. It can be seen that the models using integer charges qualitatively predict the salting out effect (i.e., the reduction of solubility of methane when adding $\mathrm{NaCl}$ ). We have also included in Fig. 2 our previous results [16] for the SD-TIP4P/2005 model obtained at a different pressure and temperature ( 1 bar, $298 \mathrm{~K}$ ) and using a different approach which involved the calculation of the chemical potential of methane via the Widom test particle method [122]. Notice that the results of this work obtained from direct coexistence runs are in acceptable agreement with the results from our previous work (specially taking into account that they were obtained at different pressure and temperature).

It is clear from the data in Fig. 2 that models with unit charges significantly overestimate the magnitude of salting out coefficient of methane. The same was found previously for noble gases by Docherty, Dyer and Cummings [123]. As can be seen in Fig. 2 the model with unit charges that best reproduces the values of salting out is the SD-SPC/E, although it deviates from experiment at high concentrations. On the other hand, models that use scaled charges reproduce much better the experimental results $[124,125]$ in the range of concentrations considered. Differences between the results of the Madrid and the Madrid-2019 force field are quite small

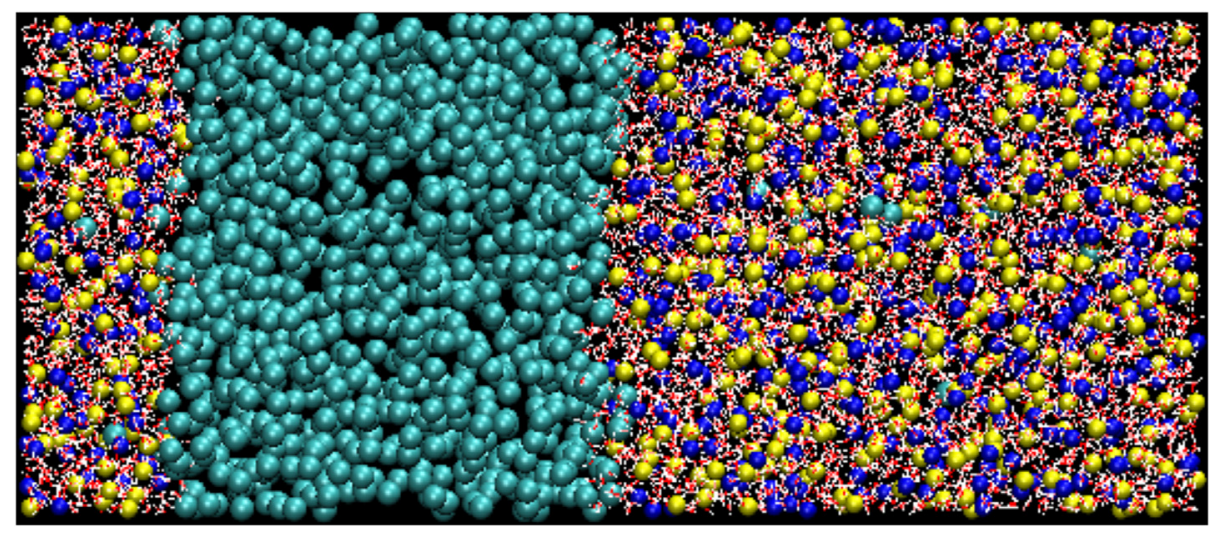

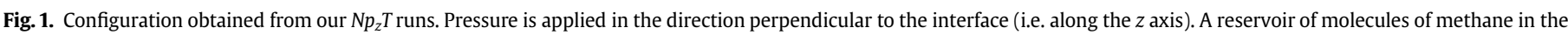

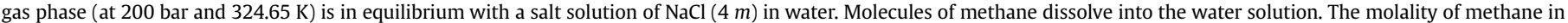

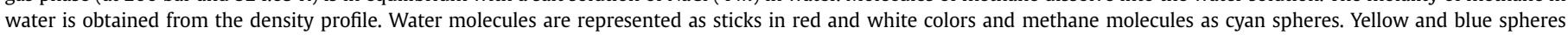
represent the salt ions $\mathrm{Cl}^{-}$and $\mathrm{Na}^{+}$, respectively). 


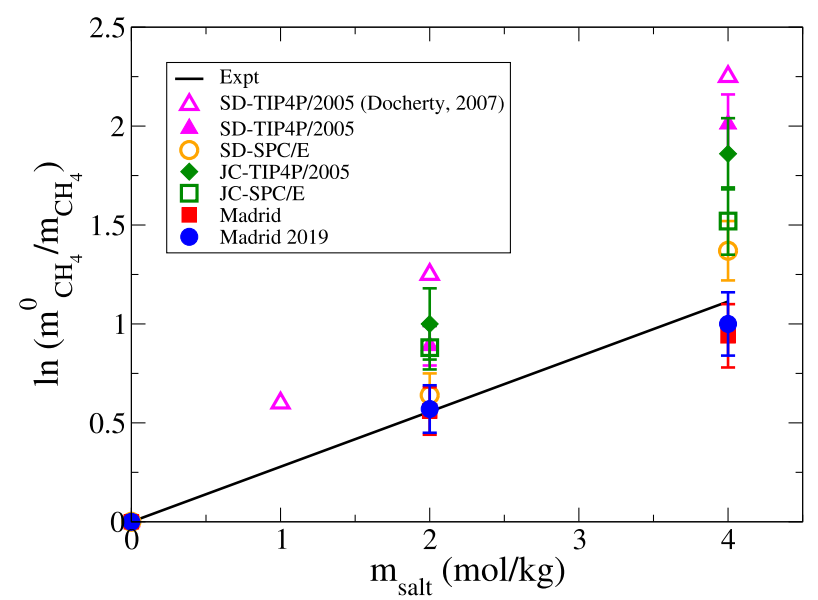

Fig. 2. Logarithm of the ratio of the molality of methane in pure water $m_{\mathrm{CH}_{4}}^{0}$ and in $\mathrm{NaCl}$ solutions $m_{\mathrm{CH}_{4}}$, as a function of the $\mathrm{m}$ of $\mathrm{NaCl} m_{\text {salt }}$. Results were obtained at 200 bar and $324.65 \mathrm{~K}$. Solid line: exp rime tal results (127); filled and empty magenta triangles: SD-TIP4P/2005 model as obtained in this work and as reported by Docherty et al. [16] (at a different pressure and temperature, namely 1 bar and $298 \mathrm{~K}$ ); orange empty circles: SD-SPC/E; green filled diamonds: JC-TIP4P/2005 model; green empty squares: JC-SPC/E; red filled squares: Madrid force field; blue filled circles: Madrid-2019 force field.

(an expected result as the parameters of the Madrid-2019 force field for $\mathrm{NaCl}$ are just a minor modification of those of the Madrid force field).

When modelling electrolytes in water one should always evaluate and discuss the number of contact ion pairs (CIP) (i.e. the number of anions in contact with one cation evaluated from the radial distribution function as explained in Ref. [86]). They are presented in Table 2 . As can be seen for the $4 \mathrm{~m}$ solution the number of CIP ranges from 0.11 (Madrid-2019), 0.15 (JC-SPC/E), 0.20 (SDTIP4P/2005), 0.22 (JC-TIP4P/2005) to 0.50 (SD-SPC/E). Thus, certain aggregation of ions exists in the concentrated solutions and this certainly may have some impact on the salting out. The number of CIP is certainly related to the solubility of the salt in water (for the considered model of salt and of water). When studying the salting out effect (and in general when modelling electrolytes in water) it is important to check that the number of CIP is not very high (say above 0.5 ) as when this occurs the physical description of the system could be wrong. Wrong densities in combination with wrong CIP could yield good estimates of salting out effect due to a cancellation of errors. This is indeed the case of the SD-SPC/E which gives a reasonable value of the salting out coefficient due to a wrong density (too low) and a high number of CIP, both factors contributing to decrease the salting out coefficient. The number of CIP ion pairs is not available from experiments. Some numbers were reported for $\mathrm{NaCl}$ by Soper and coworkers [126], but they were obtained from simulations aimed to reproduce the experimental diffraction results rather than from the neutron data (due to the low contribution of ion-ion correlations to the diffraction pattern). Soper et al. [126] reported a number of CIP ranging from $0.3(0.5)$ at low concentrations to 0.9 (1.0) at high concentrations. As can be seen the uncertainty is too high and besides they correspond to simulation rather than to experimental results. In a recent paper we have shown [127] that for a number of models of salts in water, the number of CIP at the solubility limit of the models was always below 0.5 . Thus it seems reasonable to assume that the number of CIP for $\mathrm{NaCl}$ in water for concentrations $2 \mathrm{~m}$ and $4 \mathrm{~m}$ should be below this value taking into account that the solubility of $\mathrm{NaCl}$ in water is around $6.15 \mathrm{~m}$. Certainly more experimental results on CIP on electrolytes in water would be most useful. However, the
Table 2

Number of contact ion pairs (CIP) and densities for $\mathrm{NaCl}$ solutions from the simulations of this work at 200 bar and $324.65 \mathrm{~K}$. The experimental result for the density of a $4 \mathrm{~m} \mathrm{NaCl}$ solution as reported in Ref. [128] is shown in parenthesis.

\begin{tabular}{llll}
\hline Model & $m_{\mathrm{NaCl}}(\mathrm{mol} / \mathrm{kg})$ & $\mathrm{CIP}$ & Density $\left(\mathrm{g} / \mathrm{cm}^{3}\right)$ \\
\hline Madrid-2019 & 2 & 0.06 & - \\
& 4 & 0.11 & $1.129(1.130)$ \\
SD-TIP4P/2005 & 2 & 0.10 & - \\
& 4 & 0.20 & $1.144(1.130)$ \\
JC-TIP4P/2005 & 2 & 0.12 & - \\
& 4 & 0.22 & $1.143(1.130)$ \\
JC-SPC/E & 2 & 0.07 & - \\
SD-SPC/E & 4 & 0.15 & $1.136(1.130)$ \\
& 2 & 0.22 & - \\
& 4 & 0.50 & $1.120(1.130)$ \\
\hline
\end{tabular}

evidence from simulations [127] is that at the solubility limit the number of CIP should be below 0.5 . The densities of a $4 \mathrm{~m} \mathrm{NaCl}$ solution at 200 bar and $324.65 \mathrm{~K}$ are also shown in Table 2 and compared to the experimental result. The Madrid-2019 model yields an excellent prediction of the density, followed by the JCSPC/E model. Densities of the JC-TIP4P/2005 and SD-TIP4P/2005 are higher than the experimental result by about one per cent. Density of the SD-SPC/E is lower than the experimental result by about one per cent. The salting out coefficient correlates quite well with the density. Too high densities yield too high values for the salting out coefficient. Thus to have reliable values of salting out coefficient good estimates of the densities are needed. In fact the solubility of methane is quite sensitive to the overall density of the system as was noticed by Paschek [13], and Docherty et al. [16,123].

Moreover, we have analyzed the effect of the cutoff of the potential on the salting out. We evaluated the salting out of the Madrid-2019 model in absence of salt and for a $4 \mathrm{~m} \mathrm{NaCl}$ solution increasing the cutoff value from $0.9 \mathrm{~nm}$ to $1.4 \mathrm{~nm}$. As can be seen in Table 3 the value of the solubility, both for pure water and for a $4 \mathrm{~m}$ $\mathrm{NaCl}$ solutions decreases somewhat when increasing the cutoff value. However the variation is similar in both cases so that the value of the salting out coefficient $\ln \frac{m_{\mathrm{CH} 4}^{o}}{m_{\mathrm{CH}}}$ is not much affected by the value of the cutoff.

An interesting question refers to the solvation of methane in salty solutions. For that purpose we have performed computer simulations in the $N p T$ ensemble for a system containing methane (with the number of molecules required to reproduce the solubility at 200 bar and $324.65 \mathrm{~K}$ ) and a $4 \mathrm{~m} \mathrm{NaCl}$ solution using the Madrid2019 force field. In Fig. 3 the methane-oxygen (water), methane$\mathrm{Na}^{+}$and methane- $\mathrm{Cl}^{-}$radial distribution functions are presented. As can be seen, methane is mostly surrounded by water. However some $\mathrm{Cl}^{-}$anions are able to be in contact with the methane molecule, although the $\mathrm{Na}^{+}$cations are not able to do the same. For the Madrid model the hydration energies of $\mathrm{Na}^{+}$and $\mathrm{Cl}^{-}$are both of about $65 \mathrm{~kJ} / \mathrm{mol}$ as reported by Döpke et al. [105]. Thus the energy of interaction with water is similar in both ions. Further work is needed to understand why methane- $\mathrm{Cl}^{-}$pairs are more frequent than methane- $\mathrm{Na}^{+}$pairs although it could be related to the larger size of the anion.

From the radial distribution function, the coordination numbers of methane, $n^{A}$, may be calculated as

$n^{A}=4 \pi \rho_{A} \int_{0}^{r_{\min }} g_{\mathrm{CH}_{4}-A}(r) r^{2} d r$

where $g_{\mathrm{CH}_{4}-\mathrm{A}}$ is the methane-A radial distribution function (A being either the oxygen of water, $\mathrm{Cl}^{-}$or $\mathrm{Na}^{+}$) and $\rho_{A}$ is the number density of atoms of type A. The integral upper limit $r_{\min }$ is the position of the first minimum in the radial distribution function in the cases of 
Table 3

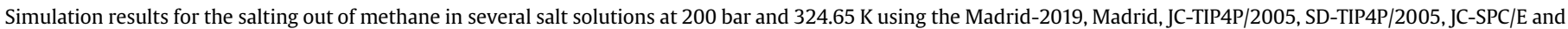

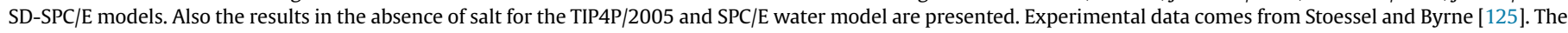

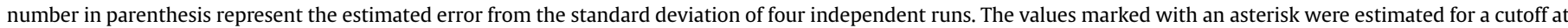
$1.4 \mathrm{~nm}$.

\begin{tabular}{|c|c|c|c|c|c|c|c|}
\hline \multirow[t]{2}{*}{ Model } & \multirow[t]{2}{*}{ Salt } & \multirow[t]{2}{*}{$T(\mathrm{~K})$} & \multirow[t]{2}{*}{$p$ (bar) } & \multirow[t]{2}{*}{$m_{\text {salt }}(\mathrm{mol} / \mathrm{kg})$} & \multirow[t]{2}{*}{$m_{\mathrm{CH}_{4}}(\mathrm{~mol} / \mathrm{kg})$} & \multicolumn{2}{|l|}{$\ln \left(\frac{m_{C_{4}}^{0}}{m_{C_{4}}}\right)$} \\
\hline & & & & & & Sim. & Exp. \\
\hline $\mathrm{SPC} / \mathrm{E}$ & - & 324.65 & 200 & 0 & $14.2(5) \times 10^{-2}$ & 0 & 0 \\
\hline \multirow[t]{2}{*}{$\mathrm{JC}-\mathrm{SPC} / \mathrm{E}$} & $\mathrm{NaCl}$ & 324.65 & 200 & 2 & $5.9(2) \times 10^{-2}$ & $0.88(11)$ & 0.56 \\
\hline & & & & 4 & $3.1(8) \times 10^{-2}$ & $1.52(17)$ & 1.11 \\
\hline \multirow[t]{2}{*}{$\mathrm{SD}-\mathrm{SPC} / \mathrm{E}$} & $\mathrm{NaCl}$ & 324.65 & 200 & 2 & $7.5(8) \times 10^{-2}$ & $0.64(11)$ & 0.56 \\
\hline & & & & 4 & $3.6(6) \times 10^{-2}$ & $1.37(15)$ & 1.11 \\
\hline \multirow[t]{2}{*}{ TIP4P/2005 } & - & 324.65 & 200 & 0 & $14.2(1) \times 10^{-2}$ & 0 & 0 \\
\hline & & & & 0 & $* 12.8(3) \times 10^{-2}$ & 0 & 0 \\
\hline \multirow[t]{2}{*}{ JC-TIP4P/2005 } & $\mathrm{NaCl}$ & 324.65 & 200 & 2 & $5.2(8) \times 10^{-2}$ & $1.00(18)$ & 0.56 \\
\hline & & & & 4 & $2.2(8) \times 10^{-2}$ & $1.86(18)$ & 1.11 \\
\hline \multirow[t]{2}{*}{ SD-TIP4P/2005 } & $\mathrm{NaCl}$ & 324.65 & 200 & 2 & $5.8(2) \times 10^{-2}$ & $0.89(10)$ & 0.56 \\
\hline & & & & 4 & $1.9(5) \times 10^{-2}$ & $2.01(15)$ & 1.11 \\
\hline \multirow[t]{2}{*}{ Madrid } & $\mathrm{NaCl}$ & 324.65 & 200 & 2 & $8.1(2) \times 10^{-2}$ & $0.56(12)$ & 0.56 \\
\hline & & & & 4 & $5.5(7) \times 10^{-2}$ & $0.94(16)$ & 1.11 \\
\hline \multirow[t]{3}{*}{ Madrid-2019 } & $\mathrm{NaCl}$ & 324.65 & 200 & 2 & $8.1(2) \times 10^{-2}$ & $0.56(12)$ & 0.56 \\
\hline & & & & 4 & $5.3(6) \times 10^{-2}$ & $0.99(16)$ & 1.11 \\
\hline & & & & 4 & $* 5.0(3) \times 10^{-2}$ & $* 0.94(15)$ & 1.11 \\
\hline Madrid-2019 & $\mathrm{KCl}$ & 324.65 & 200 & 2 & $8.7(1) \times 10^{-2}$ & $0.49(13)$ & 0.47 \\
\hline Madrid-2019 & $\mathrm{MgCl}_{2}$ & 324.65 & 200 & 2 & $5.7(1) \times 10^{-2}$ & $0.91(17)$ & 0.87 \\
\hline Madrid-2019 & $\mathrm{CaCl}_{2}$ & 324.65 & 200 & 2 & $4.3(9) \times 10^{-2}$ & $1.19(22)$ & 0.98 \\
\hline Madrid-2019 & $\mathrm{Na}_{2} \mathrm{SO}_{4}$ & 324.65 & 200 & 1.5 & $5.2(6) \times 10^{-2}$ & $1.01(13)$ & 1.25 \\
\hline Madrid-2019 & $\mathrm{K}_{2} \mathrm{SO}_{4}$ & 324.65 & 200 & 0.6 & $9.8(1) \times 10^{-2}$ & $0.37(08)$ & 0.45 \\
\hline Madrid-2019 & $\mathrm{MgSO}_{4}$ & 324.65 & 200 & 1.5 & $4.6(6) \times 10^{-2}$ & $1.13(20)$ & 0.91 \\
\hline
\end{tabular}

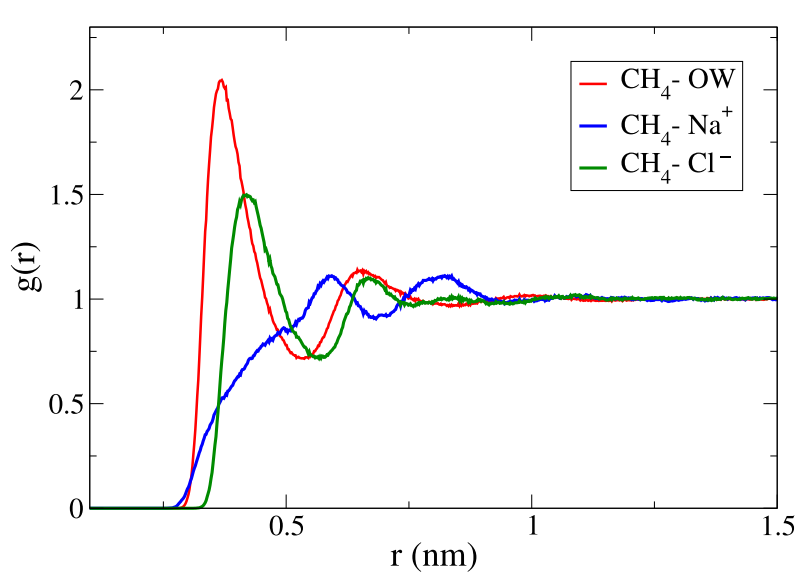

Fig. 3. Radial distribution function between methane and the oxygen of water (OW), methane- $\mathrm{Na}^{+}$, and methane- $\mathrm{Cl}^{-}$for a $4 \mathrm{~m}$ salty solution described by the Madrid-2019 force field. The number of methane molecules were chosen to reproduce the solubility of methane in the salty solution as given by the model at 200 bar and $324.6 \mathrm{~K}$.

oxygen and $\mathrm{Cl}^{-}$, and the first inflection point in the case of $\mathrm{Na}^{+}$. The hydration number of methane in the $4 \mathrm{~m}$ solution is 18.2. The corresponding coordination number is 1.3 for $\mathrm{Cl}^{-}$while only 0.3 $\mathrm{Na}^{+}$ions are in the first coordination shell of methane. Experimental reports indicate that the hydration number of methane is 20 when no salt is present [129], so our prediction seem to be in good agreement with experiment. Our results suggest that one of the molecules of water in the hydration shell is replaced by $\mathrm{Cl}^{-}$in the $\mathrm{NaCl} 4 \mathrm{~m}$ solution.

After discussing the results for $\mathrm{NaCl}$ solutions we now present the results for other electrolytes. In Table 3 the numerical data for the salting out effect of methane in several salty solutions are collected. The predictions of the Madrid-2019 model are in good agreement with experimental data for $\mathrm{NaCl}, \mathrm{KCl}, \mathrm{MgCl}_{2}$ and $\mathrm{K}_{2} \mathrm{SO}_{4}$. This is certainly satisfying as we have included divalent ions that

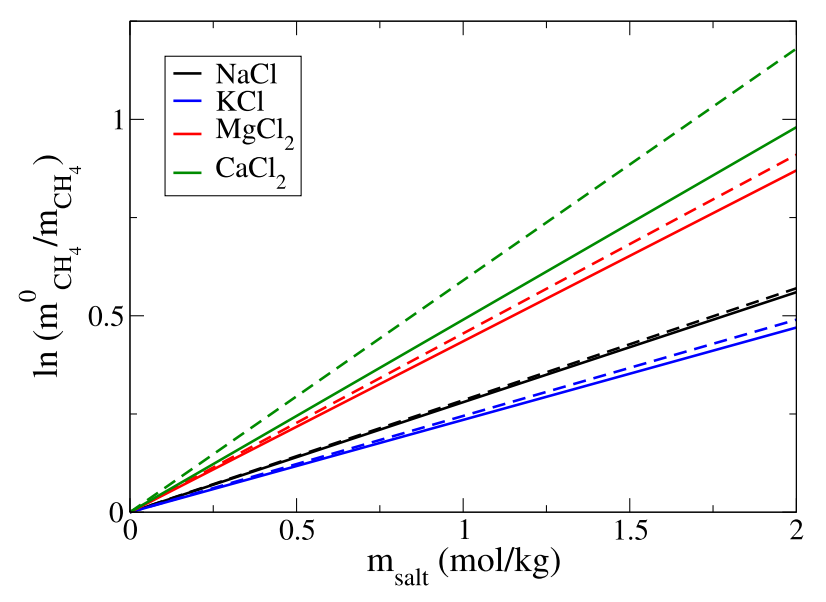

Fig. 4. Salting out of methane (200 bar and $324.65 \mathrm{~K}$ ) as obtained from computer simulations using the Madrid-2019 model. We are showing the results of different salts having chloride as the anion. The solid curve represents experimental results from Stoessel and Byrne [125]. The dashed line represents simulation results from this work.

are usually difficult to be described by common force fields. The Madrid-2019 force field slightly overestimates the salting out coefficient for $\mathrm{CaCl}_{2}$ and $\mathrm{MgSO}_{4}$ and underestimates it for $\mathrm{Na}_{2} \mathrm{SO}_{4}$ but the deviations are not too large.

The capacity of the Madrid-2019 force field to describe the correct order in the salting out of several salts containing chloride is shown in Fig. 4. This is a rather difficult test to pass. The Madrid2019 force field is able to predict correctly that the salting out coefficient of $\mathrm{KCl}$ solutions is lower than that of $\mathrm{NaCl}$ ones, when compared at the same concentration. This is in agreement with experiment. Thus for chloride salts with monovalent cations, smaller cations induce higher salting out. For divalent cations the opposite trend is found. In fact in this case the salting out effect of $\mathrm{CaCl}_{2}$ is larger than that of $\mathrm{MgCl}_{2}$. This trend is correctly described 
by simulations as shown in Fig. 4. The model also is able to capture these subtle chemical issues. Probably the physical picture can be unified if one thinks that in the case of magnesium, the true cation hydration is $\mathrm{Mg}\left(\mathrm{H}_{2} \mathrm{O}\right)_{6}^{2+}$ rather than $\mathrm{Mg}^{2+}$. The hydration number of $\mathrm{Mg}^{2+}$ is six in the Madrid-2019 force field, and this hydrated cation is certainly larger than $\mathrm{Ca}^{2+}$. This idea is supported by two facts. The first one is that the hydration free energy of $\mathrm{Mg}^{2+}$ is much larger than that of $\mathrm{Ca}^{2+}$ as has been shown recently by Döpke et al. [105] (345 vs $271 \mathrm{~kJ} / \mathrm{mol}$ ) for the Madrid-2019 model. Secondly in this model the residence time of a water molecule in $\mathrm{Ca}^{2+}$ is of about 100 ps whereas that of $\mathrm{Mg}^{2+}$ is extremely large (even in $10 \mathrm{~ns}$ no molecule of water is able to abandon the hydration layer). These numbers are in agreement with simulation and experimental results [130]. As can be seen in Fig. 4, for a certain molality the salting out of the divalent chloride cations is larger than that of monovalent cations. This can be explained in simple terms as $1 \mathrm{~mol}$ of $\mathrm{NaCl}$ generates $2 \mathrm{~mol}$ of ions, whereas $1 \mathrm{~mol}$ of $\mathrm{CaCl}_{2}$ generates $3 \mathrm{~mol}$ of ions so that an approximate factor of $2 / 3$ (or $3 / 2$ ) is expected (all other factors being identical which certainly is a severe approximation).

Although the main focus of this work was to analyze the salting out effect, the direct coexistence simulations performed allow us to obtain some information on the interfacial properties of the gas with the salty solution. In particular, the interfacial tension (IFT), $\gamma$, can be evaluated as

$\gamma=\frac{L_{z}}{2}\left(p_{z z}-\left(p_{x x}+p_{y y}\right) / 2\right)$

where $z$ is the direction perpendicular to the interface so that $p_{z z}$ and $p_{x x}, p_{y y}$ are the normal and tangent components respectively of the pressure tensor. It is important to point out that IFT are quite sensitive to the value of the cutoff at which the LJ part of the potential was truncated (Ewald sums in principle correctly include the long range ionic contributions). Thus, for a rigorous determination of $\gamma$ one should include long range corrections (LRC) [131-134] which give a positive contribution to $\gamma$. We have implemented the methodology of Lundberg and Edholm [134] and estimated this correction to be about $2 \mathrm{~mJ} / \mathrm{m}^{2}$ for the methane-water interface (the thickness of the interface was $0.28 \mathrm{~nm}$ and the magnitude of the dispersion density difference squared was $\left.\left(\Delta \rho_{C_{6}}\right)^{2} \times 10^{20}=0.15 \mathrm{~J}\right)$. This is in line with the small value of the correction found by Naeiji et al. [135]. The values obtained after including the LRC correction are presented in Table 4.

First of all let us analyze the values of $\gamma$ in the absence of salt. For the pure water-methane interface we obtained $50.8 \mathrm{~mJ} / \mathrm{m}^{2}$ usi the TIP4P/2005 water model. Experimentally, a value of about $54 \mathrm{~J} /$ $\mathrm{m}^{2}$ has been reported [100,136]. The agreement is quite reasonable. In addition, we estimate the value of $\gamma$ in absence of salt by increasing the cutoff value to $1.6 \mathrm{~nm}$ and without including longrange corrections to $\gamma$. We obtained a value of $51 \mathrm{~mJ} / \mathrm{m}^{2}$. This is very similar to the value obtained using a cutoff of $0.9 \mathrm{~nm}$ and including the long range corrections to $\gamma$ following the procedure described in Refs. [134]. For the vapor-liquid interface of pure water at this temperature the TIP4P/2005 underestimates the value of $\gamma$ by about $1-2 \mathrm{~mJ} / \mathrm{m}^{2}$ and it thus seems that a similar deviation is found for the methane-water interface. For the pure watermethane interface we obtained $47 \mathrm{~mJ} / \mathrm{m}^{2}$ using the SPC/E model of water. SPC/E underestimates the experimental value of $\gamma$ by about $7 \mathrm{~mJ} / \mathrm{m}^{2}$. Again this is similar to the deviation found at this temperature in the SPC/E model for the surface tension of the vapor-liquid interface of pure water. The conclusion is clear. If one is interested in getting a good value of $\gamma$ for the water-methane interface (with salt or without salt in the water phase), a water model that already well describes the value of $\gamma$ for the vapor-liquid interface of pure water must be used. Models such as TIP3P [92], TIP4P [92] or TIP5P [137] are not recommended for this type of studies as they yield very poor values of $\gamma$ for the vapor-liquid interface of pure water $[88,89,138]$. TIP4P/2005, followed by TIP4P-Ew [106] and SPC/E are clearly superior. This is in line with the results obtained by Sakamaki et al. [139] who compared the results of the water-pure methane interface of TIP4P/2005 with those obtained when using SPC/E showing that the agreement with experiment was much better when using TIP4P/2005.

It is interesting to point out that the prediction of the TIP4P/ 2005 model for the vapor-liquid surface tension of pure water [138] at $324 \mathrm{~K}$ is around $65 \mathrm{~mJ} / \mathrm{m}^{2}$. This means that the water-vacuum interface has a value of $\gamma$ of $65 \mathrm{~mJ} / \mathrm{m}^{2}$ (the vapor pressure of water is very low at this temperature) which reduces to about $51 \mathrm{~mJ} /$ $\mathrm{m}^{2}$ due to the methane-water interactions at the interface.

What is the impact of adding salt to the value of $\gamma$ ? It is well known that surface tension increases when adding salt to form an aqueous solution. According to the Gibbs adsorption isotherm, this implies that the ions do not adsorb on the surface of water (i.e., they have negative adsorption). Ions do not like the surface, regardless whether in the surface, vapor or methane are waiting to interact with them. They prefer to be solvated. It can be seen in Table 5 that in all the cases the value of $\gamma$ increased when adding salt. For instance, the interfacial methane-water free energy increases by about $6-7 \mathrm{~mJ} / \mathrm{m}^{2}$ when adding $\mathrm{NaCl}$ to water to form a $4 \mathrm{~m}$ solution. The effect is more pronounced for some salts than for others. It seems that $\mathrm{CaCl}_{2}$ is quite effective in increasing the interfacial energy as a $2 m$ solution increases the value of $\gamma$ by $7 \mathrm{~mJ} / \mathrm{m}^{2}$. With $\mathrm{NaCl}$ it is necessary to have a $4 \mathrm{~m}$ solution to see a similar increase.

In Fig. 5 the IFT of the methane-water solution (at 200 bar and $324.65 \mathrm{~K}$ ) is plotted as a function of the molality of the salt $(\mathrm{NaCl})$. Simulations of this work are compared to experimental values $[100,136]$. The Madrid-2019 model describes reasonably well the experimental results (although they are slightly below the experimental ones). The results of the JC-SPC/E are below those of the obtained with the TIP4P/2005 model as was discussed previously. The results for the JC-TIP4P/2005 are below the experimental ones at low concentrations but close to the experimental ones at higher concentration. Thus the JC-TIP4P/2005 overestimates the impact of the salt in the increase in the IFT. We have shifted the values of the Madrid-2019 model by $3 \mathrm{~mJ} / \mathrm{m}^{2}$ (see dashed red line in Fig. 5). As it can be seen with this shift the values of the simulations are in good agreement with experiment. Thus the Madrid-2019 seems to describe correctly the impact of the salt on the IFT. In any case, more experimental measurements on the IFT of the methane-brine system are needed to establish a solid conclusion.

Let us finish by presenting the density profile of water and methane along the interface. Results are shown for the pure watermethane interface (Fig. 6 left) using the TIP4P/2005 model for water and a $\mathrm{LJ}$ site for the methane and for the interface between a $4 \mathrm{~m} \mathrm{NaCl}$ aqueous solution and methane (Fig. 6 right) using the Madrid-2019 force field to describe the water-ion interaction. Notice that the methane molecule presents positive adsorption at the water-gas interface both for pure water and for the solution as was also found in previous work ([135,139]). Methane also shows positive adsorption when salt is added to the solution. With respect to the ions it is shown in Fig. 6 (right) that the chloride anions have a higher density than sodium cations in the proximities of the water-methane interface so that the dipole moment at the interface points out from the methane phase to water.

\section{Conclusions}

In this work we have addressed the issue of the reduction of the solubility of methane in water by the addition of salt (i.e. salting out 
Table 4

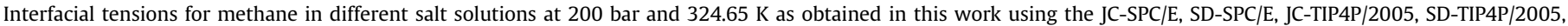

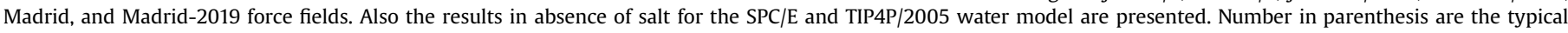

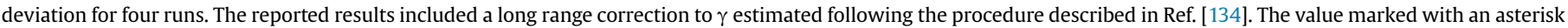
was estimated using the TIP4P/2005 water model for a cutoff at $1.6 \mathrm{~nm}$ and not including long-range corrections to $\gamma$.

\begin{tabular}{|c|c|c|c|c|c|c|}
\hline Model & Salt & $T(\mathrm{~K})$ & $p$ (bar) & $m_{\text {salt }}(\mathrm{mol} / \mathrm{kg})$ & $\gamma\left(\mathrm{mJ} / \mathrm{m}^{2}\right)$ & $\Delta \gamma\left(\mathrm{mJ} / \mathrm{m}^{2}\right)$ \\
\hline $\mathrm{SPC} / \mathrm{E}$ & - & 324.65 & 200 & 0 & $47.5(2)$ & 0 \\
\hline \multirow[t]{2}{*}{ JC-SPC/E } & $\mathrm{NaCl}$ & 324.65 & 200 & 2 & $51.3(3)$ & 3.8 \\
\hline & & & & 4 & $55.5(4)$ & 8.0 \\
\hline \multirow[t]{2}{*}{ SD-SPC/E } & $\mathrm{NaCl}$ & 324.65 & 200 & 2 & $51.3(4)$ & 3.8 \\
\hline & & & & 4 & $55.4(5)$ & 7.9 \\
\hline \multirow[t]{2}{*}{ TIP4P/2005 } & - & 324.65 & 200 & 0 & $50.8(3)$ & 0 \\
\hline & & & & 0 & $* 51.0(6)$ & 0 \\
\hline \multirow[t]{2}{*}{ JC-TIP4P/2005 } & $\mathrm{NaCl}$ & 324.65 & 200 & 2 & $54.9(5)$ & 4.1 \\
\hline & & & & 4 & $60.5(4)$ & 9.7 \\
\hline \multirow[t]{2}{*}{ SD-TIP4P/2005 } & $\mathrm{NaCl}$ & 324.65 & 200 & 2 & $55.1(2)$ & 4.3 \\
\hline & & & & 4 & $59.8(5)$ & 9.0 \\
\hline \multirow[t]{2}{*}{ Madrid } & $\mathrm{NaCl}$ & 324.65 & 200 & 2 & $53.5(4)$ & 2.7 \\
\hline & & & & 4 & $57.9(5)$ & 7.1 \\
\hline \multirow[t]{2}{*}{ Madrid-2019 } & $\mathrm{NaCl}$ & 324.65 & 200 & 2 & $53.8(2)$ & 3.0 \\
\hline & & & & 4 & $57.0(4)$ & 6.2 \\
\hline Madrid-2019 & $\mathrm{KCl}$ & 324.65 & 200 & 2 & $53.6(2)$ & 2.8 \\
\hline Madrid-2019 & $\mathrm{MgCl}_{2}$ & 324.65 & 200 & 2 & $56.0(2)$ & 5.2 \\
\hline Madrid-2019 & $\mathrm{CaCl}_{2}$ & 324.65 & 200 & 2 & $57.7(3)$ & 6.9 \\
\hline Madrid-2019 & $\mathrm{Na}_{2} \mathrm{SO}_{4}$ & 324.65 & 200 & 1.5 & $54.5(2)$ & 3.7 \\
\hline Madrid-2019 & $\mathrm{Li}_{2} \mathrm{SO}_{4}$ & 324.65 & 200 & 0.6 & $51.9(3)$ & 1.1 \\
\hline Madrid-2019 & $\mathrm{MgSO}_{4}$ & 324.65 & 200 & 1.5 & $55.4(3)$ & 4.6 \\
\hline
\end{tabular}

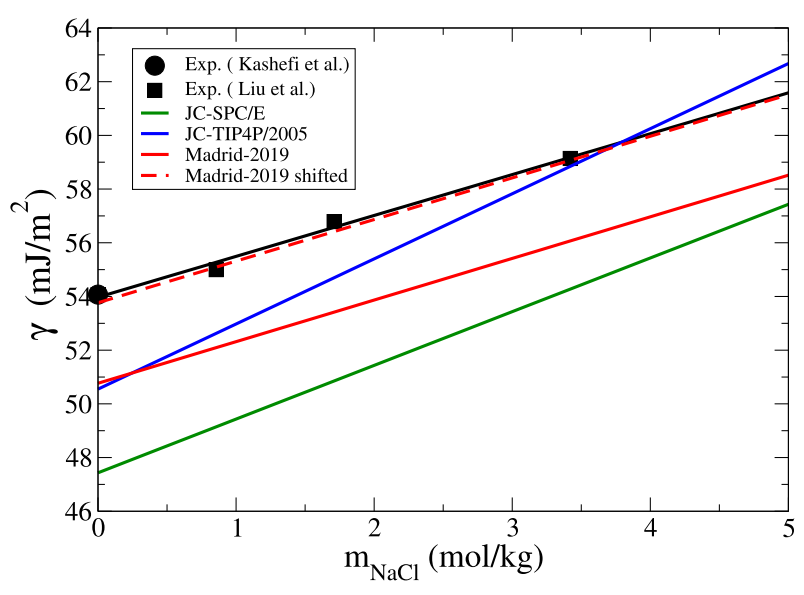

Fig. 5. Interfacial free energy at 200 bar and $324.65 \mathrm{~K}$ of the methane-aqueous $\mathrm{NaCl}$ solution as a function of the salt concentration. Symbols: experimental results taken from Kashefi et al. [100] (circle) and Liu et al. [136] (squares). The black solid line corresponds to a fit of the experimental results. Solid lines are fit to the simulation results for: Madrid-2019 (red), JC-TIP4P/2005 (blue), JC-SPC/E (green). The red dashed line was obtained by shifting $3 \mathrm{~mJ} / \mathrm{m}^{2}$ the simulation results of the Madrid-2019 model. The results for the SD-TIP4P/2005 and SD-SPC/E models (not shown) were almost identical to those obtained for the JC-TIP4P/2005 and JC-SPC/E models respectively.

effect). We have performed computer simulations to determine the salting out coefficient. The model used for water is TIP4P/2005. The methane-water interaction was tuned to reproduce the experimental value of the solubilities. For $\mathrm{NaCl}$ we have considered two type of force fields. The first family is that of models using unit charges for the ions. The second family is that which is the concept of charge scaling. The main conclusions of this work are as follows:

- The addition of salt reduces the solubility of methane which is in agreement with experiment.

- The Madrid-2019 force field is able to describe the majority of the experimental results, not only for $\mathrm{NaCl}$ but also for a number of other salts. It can then be used to obtain interesting conclusions on the salting out effect.

- Force fields that use scaled charges for the ions predict much better the salting out effect than those that do not use this idea.

- The interfacial free energies between water and a gas under pressure (methane in our study) increases with the addition of salt and the Madrid-2019 model yield results that are within $3 \mathrm{~mJ} / \mathrm{m}^{2}$ of the experimental ones.

As to the molecular origin of the salting out effect of methane in electrolyte solutions it is difficult to provide a simple explanation. Probably the best one it is that proposed by Docherty et al. [16] some time ago. They showed that the volume fraction of the solution (i.e the fraction of volume occupied by the molecules) increases (at constant $\mathrm{T}$ and $\mathrm{p}$ ) with the concentration of the salt. Higher volume fraction means that the probability of finding a cavity where methane can be inserted decreases. That provokes an increase in the excess chemical potential of methane in water, and therefore a lower solubility. In short, the electrolyte solution is more compact (higher volume fraction) than pure water and this reduces the solubility.

After reading this paper, the thoughts of the reader may go as follows. If I were interested in the problem of the solubility of methane in water then probably I should use scaled charges. This problem of salting out is probably useful for chemical engineers, but since I am not a chemical engineer and I am not working on salting out, I will continue with business as usual and I will not use scaled charges. In our opinion, the community simulating ions in water is now at a crossing point in the road. It is becoming increasingly evident that traditional non-polarizable force fields for ions are not good enough [18,46,61-63,140-142,87] (viscosities, activity coefficients, solubilities and a number of other properties been evaluated in the last ten years provide evidence of that). Certainly polarizable force fields may perform better if adequately parametrised. However, the idea of introducing scaled charges offers an intermediate route. It can be cheaper than polarizable force fields and improve the performance of non-polarizable force fields at zero cost. There is no free lunch so that these models can not describe everything. In fact the Gibbs free energy of hydration is 

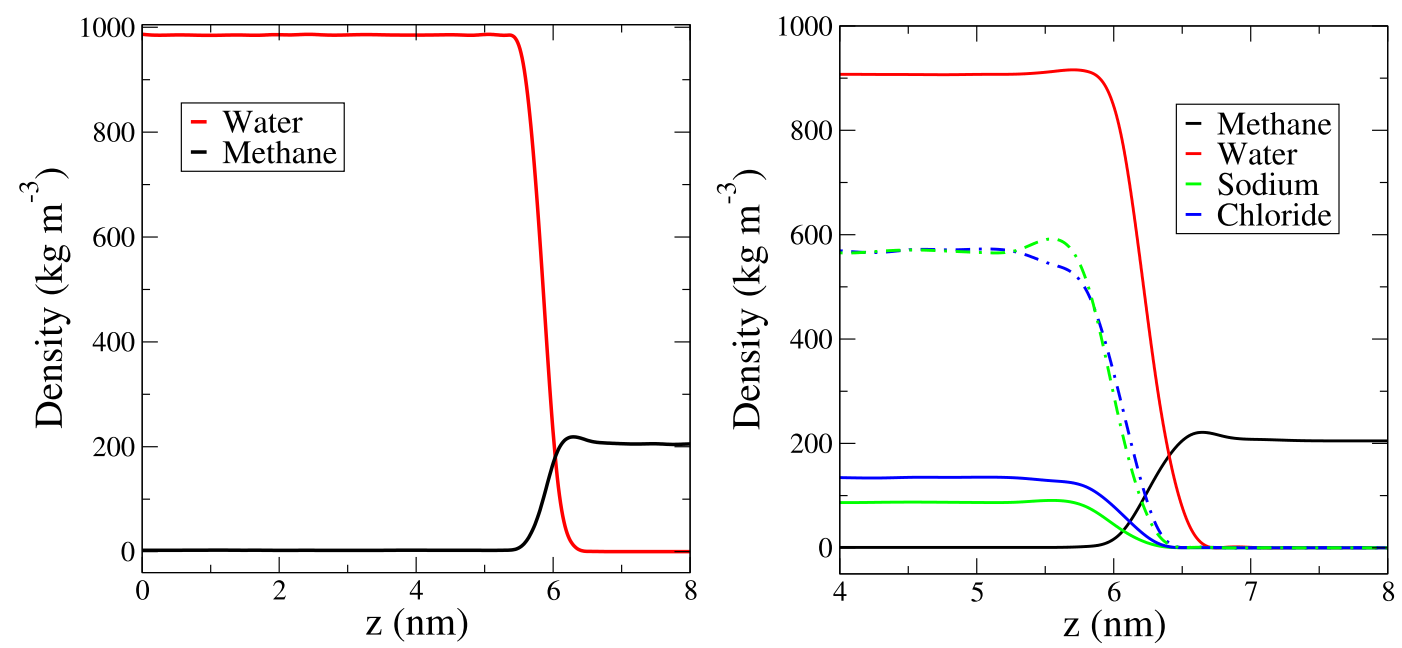

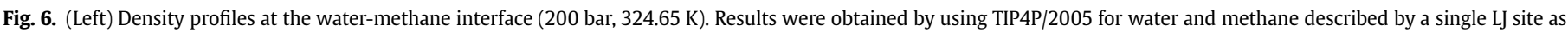

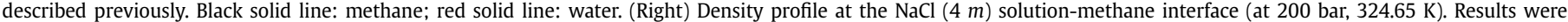

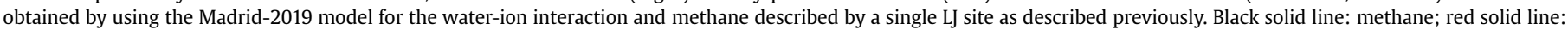

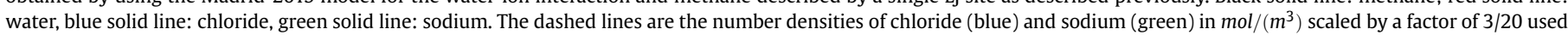
for visual clarity.

one of the properties that can not be reproduced by models using scaled charges (although in the Appendix we show that an approximate theoretical correction brings the results of simulations close to the experimental ones). We believe that the problem of salting out is an interesting problem to analyze if the impact on water properties of force fields using unit charges for the ions is too large. Further work is needed on this problem and with this work we hope to attract more people in the community to this interesting problem. The salting out effect can indeed be a school to learn more regarding force fields of ions in water. As Professor Stanley Sandler has shown in the past [143], problems that are of high practical interest such as presented in this work, can also be very useful to learn more about the fundamental aspects of the molecular description of thermodynamic properties.

\section{Declaration of competing interest}

The authors declare that they have no known competing financial interests or personal relationships that could have appeared to influence the work reported in this paper.

\section{CRediT authorship contribution statement}

S. Blazquez: Investigation, Methodology, Formal analysis. I.M. Zeron: Investigation, Methodology. M.M. Conde: Investigation, Writing - original draft, Writing - review \& editing, Funding acquisition, Supervision. J.L.F. Abascal: Writing - original draft, Investigation. C. Vega: Investigation, Writing - original draft, Writing - review \& editing, Funding acquisition, Supervision.

\section{Acknowledgments}

This work was funded by Grant No. FIS2016-78117-P of the MEC and by Project No. UCM-GR17-910570 from UCM. M.M.C. acknowledges CAM and UPM for financial support of this work through the CavitieS project No. APOYO-JOVENES-01HQ1S-129B5E4MM from "Accion financiada por la Comunidad de Madrid en el marco del Convenio Plurianual con la Universidad Politecnica de Madrid en la linea de actuacion estimulo a la investigacion de jovenes doctores". The authors gratefully acknowledge the
Universidad Politécnica de Madrid (www.upm.es) for providing computing resources on Magerit Supercomputer. We thank Dr. Carl McBride for a critical reading of the manuscript. I.M.Z. thanks CONACYT (Mexico) for the financial support: "Convocatoria 2018 de apoyo para estancias postdoctorales en el extranjero vinculadas a la consolidacion de grupos de investigacion y fortalecimiento del posgrado nacional"

\section{Appendix1. Correction to the hydration free energy of models with scaled charges}

A property that is often used when designing force fields of ions in water is the Gibbs free energy of hydration. The Gibbs free energy of hydration is defined as the change in Gibbs free energy when a mole of ions in the ideal gas at a given temperature and pressure are transferred to pure water (i.e. infinite dilution) at the same temperature and pressure. Notice that some authors use a slightly different criteria as they transfer the ions at constant temperature and volume to water (with this last convention the hydration free energy corresponds to the excess contribution to the chemical potential).

In general, models that use scaled charges are not able to reproduce the hydration free energies found in experiments. In fact the chemical potentials and hydration free energies of salts tend to be smaller (in absolute value) than those from experiments [85,144]. However it is interesting to point out that Leontyev and Stuchebrukhov [75] suggested to use a theoretical correction (denoted as $\Delta G_{e l}$ ) which for a 1:1 electrolyte is given by:

$\Delta G_{e l}=\left(1-\frac{1}{\varepsilon_{e l}}\right)\left(\frac{q_{\text {scaled }}^{2}}{2 R_{+}}+\frac{q_{\text {scaled }}^{2}}{2 R_{-}}\right)$

In this expression $R_{+}$and $R_{-}$are the radius of the cation and anion respectively and $\varepsilon_{e l}$ is related to the electronic contribution to the dielectric constant of water $\left(\varepsilon_{e l}=1 /\left(q_{\text {scaled }} / e\right)^{2}\right)$ where $e$ is the charge of the electron. This formula is similar to the Born expression for the hydration free energy of an ion but with the dielectric constant of water replaced by the electronic contribution to it (which has a value smaller than two). When the radius is expressed in $\AA$ the correction to the hydration free energy in $\mathrm{kJ} / \mathrm{mol}$ is 
obtained as:

$$
\begin{aligned}
\Delta G_{e l} /(k J / m o l)= & -1387.7\left(1-\left(\frac{q_{\text {scaled }}}{e}\right)^{2}\right) \\
& \left(\frac{\left(q_{\text {scaled }} / e\right)^{2}}{2 R_{+}(\AA)}+\frac{\left(q_{\text {scaled }} / e\right)^{2}}{2 R_{-}(\AA)}\right)
\end{aligned}
$$

The previous formula is for a 1:1 electrolyte. For a 1:2 electrolyte as $\mathrm{MgCl}_{2}$ one should use

$$
\Delta G_{e l} /(k J / m o l)=-1387.7\left(1-\left(\frac{q_{\text {scaled }}}{e}\right)^{2}\right)
$$

presented in Table 5 and the agreement with experimental results $[146,147]$ is quite reasonable. We also present in Table 5 the results obtained from the prescription proposed by Döpke et al. [105] which also brings the MD values into reasonable agreement with the experimental ones. In Table 5 we have also shown the results obtained by using another simple approximation for the correction term. As at high dilution the ions interact mainly with water, and as the charges of the ions are scaled by a factor $q_{\text {scaled }} / e$, one may assume that the interaction energy with water is scaled by a similar factor. Thus this second prescription yields:

$$
\Delta G_{\text {total }}^{\text {this work }}{ }^{1 / q}=\Delta G_{M D} /\left(q_{\text {scaled }} / e\right)
$$

where $\Delta G_{M D}$ is the Gibbs free energy of hydration obtained from MD simulations of the model with scaled charges. With this correction the results tend to be somewhat lower than the experimental ones (see the results in Table 5).

\section{Table 5}

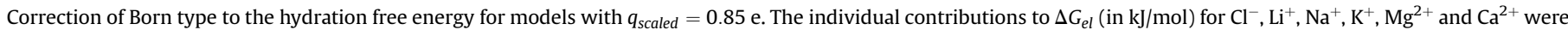

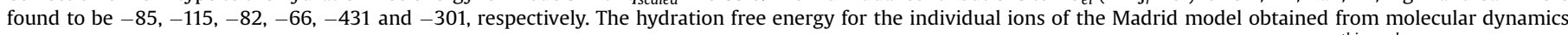

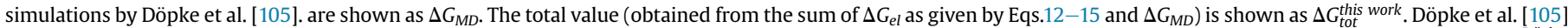

\begin{tabular}{|c|c|c|c|c|c|c|c|}
\hline Salt & $\Delta G_{e l}$ & $\Delta G_{M D}$ & $\Delta G_{\text {tot }}^{\text {this work }}$ & $\Delta G_{\text {tot }}^{\text {this work }} 1 / q$ & $\Delta G_{\text {tot }}^{\text {Döpke }} 1 / q^{2}$ & $\Delta G_{\text {exp }}^{\text {Schmid }}$ & $\Delta G_{\text {exp }}^{\text {Marcus }}$ \\
\hline $\mathrm{LiCl}$ & -200 & -661 & -861 & -778 & -915 & -849 & -815 \\
\hline $\mathrm{NaCl}$ & -167 & -550 & -717 & -647 & -761 & -744 & -705 \\
\hline $\mathrm{KCl}$ & -151 & -498 & -649 & -586 & -689 & -671 & -635 \\
\hline $\mathrm{MgCl}_{2}$ & -601 & -2012 & -2613 & -2367 & -2785 & - & -2518 \\
\hline $\mathrm{CaCl}_{2}$ & -471 & -1699 & -2170 & -1999 & -2352 & - & -2195 \\
\hline
\end{tabular}

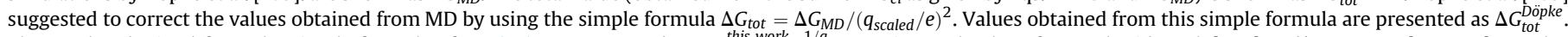

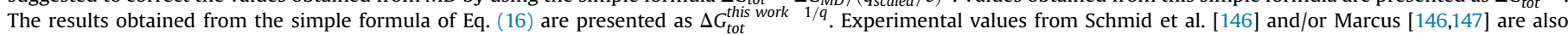
presented in the last two columns. All reported values of the Gibbs free energies are shown in $\mathrm{kJ} / \mathrm{mol}$.

$$
\left(\frac{\left(2 q_{\text {scaled }} / e\right)^{2}}{2 R_{+}(\AA)}+\frac{2\left(q_{\text {scaled }} / e\right)^{2}}{2 R_{-}(\AA)}\right),
$$

where one is taking into account that the charge of the cation is twice $q_{\text {scaled }}$ and that the salt has two chloride anions.

Obviously when $q_{\text {scaled }} / e=1$ the value of the correction is zero. For the Madrid model of $\mathrm{NaCl} q_{\text {scaled }}=0.85$ e. It is difficult to estimate the radius of the ion. Marcus [145] suggested to consider the ion-water distance in solution $d_{\text {ion-water }}$ (as given by the position of the first peak of the ion-oxygen distribution function) and to subtract the contribution of water. However it is difficult to estimate which is the contribution of water. Taking into account that water orients in a different way to cations and anions Schmid et al. [146] suggested to use the following expression for the radius of a cation and of an anion:

$R_{\text {cation }}=d_{\text {cation-water }}-0.63 \AA$,

$R_{\text {anion }}=d_{\text {anion-water }}-1.40 \AA$,

where $0.63 \AA$ is the covalent radius of oxygen and $1.40 \AA$ is the estimated value of the radius of water. We shall use these values in this work.

Values of $d_{\text {ion-water }}$ for the Madrid-2019 were reported in our previous work [86]. In Table 5 the estimates of the correction term for each individual ion and for each individual salt are presented. The hydration Gibbs free energy of the ions of the Madrid model have been obtained recently by Döpke et al. [105]. The results obtained after adding the correction term and the MD value are
In summary, the hydration free energies of models with scaled charges can be corrected with a theoretical expression of the Born type that brings the results into reasonable agreement with experiment.

\section{References}

[1] A.Y. Shcherbina, L.D. Talley, D.L. Rudnick, Science 302 (2003) 1952.

[2] W. Cantrell, A. Heymsfield, Bull. Am. Meteorol. Soc. 86 (2005) 795.

[3] S. Klotz, L.E. Bove, T. Strässle, T.C. Hansen, A.M. Saitta, Nat. Mater. 8 (2009) 405.

[4] T. Humplik, J. Lee, S.C. O'Hern, B.A. Fellman, M.A. Baig, S.F. Hassan, M.A. Atieh, F. Rahman, T. Laoui, R. Karnik, E.N. Wang, Nanotechnology 22 (2011) 292001.

[5] G.J. Morris, E. Acton, Cryobiology 66 (2013) 85.

[6] G. Bullock, V. Molinero, Faraday Discuss 167 (2013) 371.

[7] L.E. Bove, R. Gaal, Z. Raza, A.A. Ludl, S. Klotz, A.M. Saitta, A.F. Goncharov, P. Gillet, Proc. Natl. Acad. Sci. U.S.A. 112 (2015) 8216.

[8] M.M. Conde, M. Rovere, P. Gallo, Phys. Chem. Chem. Phys. 19 (2017) 9566.

[9] J.B. Klauda, S.I. Sandler, Energy Fuels 19 (2005) 459.

[10] E.D. Sloan, Nature 426 (2003) 353.

[11] G. Graziano, J. Chem. Phys. 129 (2008), 084506.

[12] B. Guillot, Y. Guissani, J. Chem. Phys. 99 (1993) 8075.

[13] D. Paschek, J. Chem. Phys. 120 (2004) 6674.

[14] J.L.F. Abascal, C. Vega, J. Chem. Phys. 123 (2005) 234505.

[15] H. Docherty, A. Galindo, C. Vega, E. Sanz, J. Chem. Phys. 125 (2006), 074510.

[16] H. Docherty, A. Galindo, C. Vega, E. Sanz, J. Phys. Chem. B 111 (2007) 8993.

[17] R.B. Best, W. Zheng, J. Mittal, J. Chem. Theor. Comput. 10 (2014) 5113.

[18] W.R. Smith, I. Nezbeda, J. Kolafa, F. Moučka, Fluid Phase Equil. 466 (2018) 19.

[19] J. Chandrasekhar, D.C. Spellmeyer, W.L. Jorgensen, J. Am. Chem. Soc. 106 (1984a) 903.

[20] T. Straatsma, H. Berendsen, J. Chem. Phys. 89 (1988) 5876.

[21] J. Aqvist, J. Phys. Chem. 94 (1990) 8021.

[22] L.X. Dang, J. Chem. Phys. 96 (1992) 6970.

[23] D. Beglov, B. Roux, J. Chem. Phys. 100 (1994) 9050.

[24] D.E. Smith, L.X. Dang, J. Chem. Phys. 100 (1994) 3757.

[25] B. Roux, Biophys. J. 71 (1996) 3177.

[26] Z. Peng, C.S. Ewig, M.-J. Hwang, M. Waldman, A.T. Hagler, J. Phys. Chem. 101 (1997) 7243.

[27] S. Weerasinghe, P.E. Smith, J. Chem. Phys. 119 (2003) 11342. 
[28] K.P. Jensen, W.L. Jorgensen, J. Chem. Theor. Comput. 2 (2006) 1499.

[29] G. Lamoureux, B. Roux, J. Phys. Chem. B 110 (2006) 3308.

[30] J. Alejandre, J.-P. Hansen, Phys. Rev. E 76 (2007), 061510.

[31] P.J. Lenart, A. Jusufi, A.Z. Panagiotopoulos, J. Chem. Phys. 126 (2007), 044509

[32] I.S. Joung, T.E. Cheatham, J. Phys. Chem. B 112 (2008) 9020.

[33] D. Corradini, M. Rovere, P. Gallo, J. Chem. Phys. 132 (2010) 134508.

[34] K.M. Callahan, N.N. Casillas-Ituarte, M. Roeselová, H.C. Allen, D.J. Tobias, J. Phys. Chem. 114 (2010) 5141.

[35] H. Yu, T.W. Whitfield, E. Harder, G. Lamoureux, I. Vorobyov, V.M. Anisimov, A.D. MacKerell Jr., B. Roux, J. Chem. Theor. Comput. 6 (2010) 774.

[36] M.M. Reif, P.H. Hünenberger, J. Chem. Phys. 134 (2011) 144104.

[37] M.B. Gee, N.R. Cox, Y. Jiao, N. Bentenitis, S. Weerasinghe, P.E. Smith, J. Chem Theor. Comput. 7 (2011) 1369.

[38] S. Deublein, J. Vrabec, H. Hasse, J. Chem. Phys. 136 (2012), 084501.

[39] A.H. Mao, R.V. Pappu, J. Chem. Phys. 137 (2012), 064504.

[40] S. Mamatkulov, M. Fyta, R.R. Netz, J. Chem. Phys. 138 (2013), 024505.

[41] F. Moučka, I. Nezbeda, W.R. Smith, J. Chem. Theor. Comput. 9 (2013a) 5076.

[42] P.T. Kiss, A. Baranyai, J. Chem. Phys. 141 (2014) 114501.

[43] J. Kolafa, J. Chem. Phys. 145 (2016) 204509.

[44] R. Elfgen, M. Hülsmann, A. Krämer, T. Köddermann, K.N. Kirschner, D. Reith, Eur. Phys. J. Spec. Top. 225 (2016) 1391.

[45] I. Pethes, J. Mol. Liq. 242 (2017) 845

[46] A.K. Giri, E. Spohr, J. Mol. Liq. 228 (2017) 63.

[47] J. Chandrasekhar, D.C. Spellmeyer, W.L. Jorgensen, J. Am. Chem. Soc. 106 (1984b) 903

[48] M. Patra, M. Karttunen, J. Comput. Chem. 25 (2004) 678.

[49] H. Jiang, P.G. Debenedetti, A.Z. Panagiotopoulos, J. Chem. Phys. 150 (2019) 124502.

[50] G. Lanaro, G.N. Patey, J. Phys. Chem. B 120 (2016) 9076.

[51] H.J.C. Berendsen, J.R. Grigera, T.P. Straatsma, J. Phys. Chem. 91 (1987) 6269.

[52] H. Jiang, A. Haji-Akbari, P.G. Debenedetti, A.Z. Panagiotopoulos, J. Chem. Phys. 148 (2018), 044505.

[53] A.K. Mazur, J. Am. Chem. Soc. 125 (2003) 7849.

[54] J. Alejandre, G.A. Chapela, F. Bresme, J.-P. Hansen, J. Chem. Phys. 130 (2009) 174505.

[55] F. Moučka, M. Lísal, W.R. Smith, J. Phys. Chem. B 116 (2012) 5468.

[56] F. Moučka, I. Nezbeda, W.R. Smith, J. Chem. Phys. 138 (2013) 154102.

[57] P. Auffinger, T.E. Cheatham, A.C. Vaiana, J. Chem. Theor. Comput. 3 (2007) 1851.

[58] T. Martinek, E. Duboué-Dijon, S. Timr, P.E. Mason, K. Baxová, H.E. Fischer, B. Schmidt, E. Pluhařová, P. Jungwirth, J. Chem. Phys. 148 (2018) 222813.

[59] E. Wernersson, P. Jungwirth, J. Chem. Theor. Comput. 6 (2010) 3233.

[60] E. Pluhařová, P.E. Mason, P. Jungwirth, J. Phys. Chem. 117 (2013) 11766.

[61] Z. Mester, A.Z. Panagiotopoulos, J. Chem. Phys. 143 (2015), 044505.

[62] Z. Mester, A.Z. Panagiotopoulos, J. Chem. Phys. 142 (2015), 044507.

[63] J.R. Espinosa, J.M. Young, H. Jiang, D. Gupta, C. Vega, E. Sanz, P.G. Debenedetti A.Z. Panagiotopoulos, J. Chem. Phys. 145 (2016) 154111.

[64] H. Jiang, P.G. Debenedetti, A.Z. Panagiotopoulos, J. Chem. Phys. 149 (2018) 141102.

[65] J.L. Aragones, E. Sanz, C. Vega, J. Chem. Phys. 136 (2012) 244508.

[66] A.L. Benavides, J.L. Aragones, C. Vega, J. Chem. Phys. 144 (2016) 124504.

[67] H. Jiang, Z. Mester, O.A. Moultos, I.G. Economou, A.Z. Panagiotopoulos, J. Chem. Theor. Comput. 11 (2015) 3802.

[68] P.T. Kiss, A. Barayai, J. Chem. Phys. 138 (2013) 204507.

[69] G.A. Orozco, O.A. Moultos, H. Jiang, I.G. Economou, A.Z. Panagiotopoulos, J. Chem. Phys. 141 (2014) 234507.

[70] J.S. Kim, Z. Wu, A.R. Morrow, A. Yethiraj, A. Yethiraj, J. Phys. Chem. B 116 (2012) 12007.

[71] Z. Kann, J. Skinner, J. Chem. Phys. 141 (2014) 104507.

[72] I.V. Leontyev, A.A. Stuchebrukhov, J. Chem. Phys. 130 (2009), 085102.

[73] I.V. Leontyev, A.A. Stuchebrukhov, J. Chem. Theor. Comput. 6 (2010) 3153.

[74] I.V. Leontyev, A.A. Stuchebrukhov, J. Chem. Theor. Comput. 6 (2010) 1498.

[75] I.V. Leontyev, A.A. Stuchebrukhov, Phys. Chem. Chem. Phys. 13 (2011) 2613.

[76] I.V. Leontyev, A.A. Stuchebrukhov, J. Chem. Theor. Comput. 8 (2012) 3207.

[77] I.V. Leontyev, A.A. Stuchebrukhov, J. Chem. Phys. 141 (2014), 014103.

[78] C. Vega, Mol. Phys. 113 (2015) 1145.

[79] M. Jorge, L. Lue, J. Chem. Phys. 150 (2019), 084108.

[80] M. Kohagen, P.E. Mason, P. Jungwirth, J. Phys. Chem. B 118 (2014) 7902.

[81] M. Kohagen, P.E. Mason, P. Jungwirth, J. Phys. Chem. B 120 (2016) 1454

[82] R. Fuentes-Azcatl, M.C. Barbosa, J. Phys. Chem. B 120 (2016) 2460.

[83] J. Li, F. Wang, J. Chem. Phys. 143 (2015) 194505.

[84] J. Li, F. Wang, J. Phys. Chem. B 121 (2017) 6637.

[85] A.L. Benavides, M.A. Portillo, V.C. Chamorro, J.R. Espinosa, J.L.F. Abascal, C. Vega, J. Chem. Phys. 147 (2017) 104501.

[86] I.M. Zeron, J.L.F. Abascal, C. Vega, J. Chem. Phys. 151 (2019) 134504.

[87] S. Yue, A.Z. Panagiotopoulos, Mol. Phys. 117 (2019) 3538.

[88] C. Vega, J.L.F. Abascal, Phys. Chem. Chem. Phys. 13 (2011) 19663.

[89] C. Vega, J.L.F. Abascal, M.M. Conde, J.L. Aragones, Faraday Discuss 141 (2009) 251.

[90] J.L.F. Abascal, C. Vega, J. Chem. Phys. 134 (2011) 186101.
[91] M.M. Conde, M.A. Gonzalez, J.L.F. Abascal, C. Vega, J. Chem. Phys. 139 (2013) 154505.

[92] W.L. Jorgensen, J. Chandrasekhar, J.D. Madura, R.W. Impey, M.L. Klein, J. Chem. Phys. 79 (1983) 926.

[93] E. Sanz, C. Vega, J.L.F. Abascal, L.G. MacDowell, Phys. Rev. Lett. 92 (2004) 255701.

[94] L.G. MacDowell, E. Sanz, C. Vega, J.L.F. Abascal, J. Chem. Phys. 121 (2004) 10145.

[95] C. Vega, M. Martin-Conde, A. Patrykiejew, Mol. Phys. 104 (2006) 3583.

[96] J.L.F. Abascal, C. Vega, J. Phys. Chem. C 111 (2007) 15811.

[97] P.J. Dyer, H. Docherty, P.T. Cummings, J. Chem. Phys. 129 (2008), 024508.

[98] H.S. Ashbaugh, N.J. Collet, H.W. Hatch, J.A. Staton, J. Chem. Phys. 132 (2010) 124504.

[99] O.L. Culberson, J.J. McKetta, J. Petrol. Technol. 3 (1951) 223.

[100] K. Kashefi, L.M.C. Pereira, A. Chapoy, R. Burgass, B. Tohidi, Fluid Phase Equil, 409 (2016) 301.

[101] D. Ballal, P. Venkataraman, W.A. Fouad, K.R. Cox, W.G. Chapman, J. Chem. Phys. 141 (2014), 064905.

[102] D. Ballal, D. Asthagiri, A.V. Parambathu, P. Venkataraman, W.A. Fouad, K.R. Cox, W.G. Chapman, J. Chem. Phys. 145 (2016) 119901.

[103] Y. Yang, A.K.N. Nair, S. Sun, J. Phys. Chem. B 121 (2017) 9688.

[104] W. Li, Z. Jin, Fuel 254 (2019) 115657.

[105] M.F. Döpke, O.A. Moultos, R. Hartkamp, J. Chem. Phys. 152 (2020), 024501.

[106] H.W. Horn, W.C. Swope, J.W. Pitera, J.D. Madura, T.J. Dick, G.L. Hura, T. HeadGordon, J. Chem. Phys. 120 (2004) 9665.

[107] Z. Mester, A.Z. Panagiotopoulos, J. Chem. Phys. 142 (2015) 44507.

[108] A.J.C. Ladd, L. Woodcock, Chem. Phys. Lett. 51 (1977) 155.

[109] A.J.C. Ladd, L. Woodcock, Mol. Phys. 36 (1978) 611.

[110] J. Cape, L. Woodcock, Chem. Phys. Lett. 59 (1978) 271

[111] R.G. Fernandez, J.L.F. Abascal, C. Vega, J. Chem. Phys. 124 (2006) 144506.

[112] D. van der Spoel, E. Lindahl, B. Hess, G. Groenhof, A.E. Mark, H.J.C. Berendsen, J. Comput. Chem. 26 (2005) 1701.

[113] B. Hess, C. Kutzner, D. van der Spoel, E. Lindahl, J. Chem. Theor. Comput. 4 (2008) 435 .

[114] D. Beeman, J. Comput. Phys. 20 (1976) 130.

[115] S. Nosé, Mol. Phys. 52 (1984) 255.

[116] W.G. Hoover, Phys. Rev. A 31 (1985) 1695.

[117] M. Parrinello, A. Rahman, J. Appl. Phys. 52 (1981) 7182.

[118] U. Essmann, L. Perera, M.L. Berkowitz, T. Darden, H. Lee, L.G. Pedersen, J. Chem. Phys. 103 (1995) 8577.

[119] B. Hess, H. Bekker, H.J.C. Berendsen, J.G.E.M. Fraaije, J. Comput. Chem. 18 (1997) 1463.

[120] B. Hess, J. Chem. Theor. Comput. 4 (2008) 116.

[121] J.P. Ryckaert, G. Ciccotti, H.J. Berendsen, J. Comput. Phys. 23 (1977) 327.

[122] B. Widom, J. Chem. Phys. 39 (1963) 2808.

[123] H. Docherty, P.J. Dyer, P.T. Cummings, Mol. Simulat. 41 (2011) 3282

[124] T.D. O'Sullivan, N.O. Smith, J. Phys. Chem. 74 (1970) 1460.

[125] R.K. Stoessell, P.A. Byrne, Geochem. Cosmochim. Acta 46 (1982) 1327.

[126] R. Mancinelli, A. Botti, F. Bruni, M.A. Ricci, A.K. Soper, J. Phys. Chem. B 111 (2007) 13570.

[127] A.L. Benavides, M.A. Portillo, J.L.F. Abascal, C. Vega, Mol. Phys. 115 (2017) 1301.

[128] R.W. Potter, D.L. Brown, The volumetric properties of aqueous sodium chloride solutions from O degrees to 500 degrees C at pressures up to 2000 bars based on a regression of available data in the literature, Tech. Rep. $1421 C$ (1977). USGS.

[129] S.F. Dec, K.E. Bowler, L.L. Stadterman, C.A. Koh, E.D. Sloan, J. Am. Chem. Soc. 128 (2006) 414

[130] J.P. Larentzos, L.J. Criscenti, J. Phys. Chem. B 112 (2008) 14243.

[131] A. Ghoufi, P. Malfreyt, D.J. Tildesley, Chem. Soc. Rev. 45 (2016) 1387.

[132] J. Rowlinson, B. Widom, Molecular Theory of Capillarity, Clarendon, Oxford, 1982.

[133] J. Alejandre, D. Tildesley, G.A. Chapela, J. Chem. Phys. 102 (1995) 4574.

[134] L. Lundberg, O. Edholm, J. Chem. Theor. Comput. 12 (2016) 4025.

[135] P. Naeiji, T.K. Woo, S. Alavi, F. Varaminian, R. Ohmura, J. Chem. Phys, 150 (2019) 114703.

[136] Y. Liu, H.A. Li, R. Okuno, Ind. Eng. Chem. Res. 55 (2016) 12358.

[137] M.W. Mahoney, W.L. Jorgensen, J. Chem. Phys. 112 (2000) 8910.

[138] C. Vega, E. de Miguel, J. Chem. Phys. 126 (2007) 154707.

[139] R. Sakamaki, A.K. Sum, T. Narumi, R. Ohmura, K. Yasuoka, J. Chem. Phys. 134 (2011) 144702.

[140] F. Moučka, M. Lísal, J. Škvor, J. Jirsák, I. Nezbeda, W.R. Smith, J. Phys. Chem. B 115 (2011) 7849.

[141] F. Moučka, M. Lisal, W.R. Smith, J. Phys. Chem. B 116 (2012) 5468.

[142] I. Nezbeda, F. Moučka, W.R. Smith, Mol. Phys. 114 (2016) 1665.

[143] J.A. Myers, S.I. Sandler, R.H. Wood, Ind. Eng. Chem. Res. 41 (2002) 3282.

[144] A. Nikitin, G. Del Frate, J. Comput. Chem. 24 (2019) 2464.

[145] Y. Marcus, Chem. Rev. 88 (1988) 1475.

[146] R. Schmid, A.M. Miah, V.N. Sapunov, Phys. Chem. Chem. Phys. 2 (2000) 97.

[147] Y. Marcus, Ion Properties, Marcel Dekker, Inc, 1997. 